\title{
An Economic Analysis of Low Cost Carriers and Insurance
}

\author{
Mahito Okura ${ }^{1}$ \\ ${ }^{1}$ Department of Social System Studies, Faculty of Contemporary Social Studies, Doshisha Women's College of Liberal \\ Arts, Kyoto, Japan. \\ Correspondence: Mahito Okura, Department of Social System Studies, Faculty of Contemporary Social Studies, \\ Doshisha Women's College of Liberal Arts, Kodo, Kyotanabe, Kyoto, 610-0395, Japan.
}

Received: July 17, 2015

Accepted: July 28, 2015

Available online: August 13, 2015

doi:10.11114/aef.v2i4.1029

URL: http://dx.doi.org/10.11114/aef.v2i4.1029

\begin{abstract}
The purpose of this research is to analyze an airline market in which both low cost carriers (LCCs) and full service carriers (FSCs) coexist. LCCs propose cheaper air ticket prices, but the possibility of late arrival is higher than with FSCs. This research investigates the effect of the introduction of an insurance policy that covers the losses from late arrivals. In relation to this insurance, the following two questions are considered. The first is how the demand for LCC changes when the insurance is introduced. The second is how the introduction of this insurance influences the LCC's investments to lower the possibility of late arrivals. The main results of this research are as follows. First, the introduction of late-arrival insurance increases the demand for LCC. Second, the impact of the introduction of this insurance becomes high when the possibility of late arrival is high and the insurance premium rate is low; however, the effect of the air ticket price of LCC is ambiguous. Third, the introduction of this insurance reduces an LCC's optimal investment to lower the possibility of late arrivals.
\end{abstract}

Keywords: low cost carrier (LCC), full service carrier (FSC), insurance

\section{Introduction}

In Japan, low cost carrier (LCC) services have developed rapidly, especially in recent years. According to a committee report from the Ministry of Land, Infrastructure, Transport, and Tourism (MLIT), the market share of LCCs in Japanese domestic airlines was 7.5 percent in March 2014, while it was 0.9 percent in March 2012. (Notes 1,2) The main reason for the increasing market share of LCCs seems to be that three new LCCs-Air Asia Japan (Vanilla Air), Jetstar Japan, and Peach Aviation - started service in 2012. (Note 3)

Roughly speaking, LCCs can propose cheaper air ticket prices than full service carriers (FSCs) as compensation for the lack of multiple kinds of services such as wide seat capacity, free drink service, and so on. (Note 4) In order to compare the respective air ticket prices, we considered the flight from Tokyo-Narita to Fukuoka, because both Japan Airline (FSC) and Jetstar Japan (LCC) provide services on this route. We obtained the air ticket prices specified for September 15, 2015 through each website. (Note 5) The ticket prices of Japan Airline and Jetstar Japan are 14,640 (cheapest price) and 7,690 (average price) Japanese yen, respectively. (Note 6) This investigation shows that LCCs have huge advantages in price competition.

However, LCCs have several disadvantages. One of these disadvantages is that LCCs have a higher possibility of late arrival than FSCs. According to information from the MLIT, the average rate of late departure of two FSCs in Japan (Japan Airline and All Nippon Airways) in fiscal 2014 was 7.30 percent, while that of LCCs in Japan (Vanilla Air, Jetstar Japan, Peach Aviation, and Spring Airline Japan) in fiscal 2014 was 16.12 percent. (Note 7) This investigation demonstrates that LCCs have more disadvantages regarding on-time arrivals than FSCs. (Note 8) From this viewpoint, we know that individuals whose schedules at the final destination are tight and for whom punctuality is important have a tendency to avoid using LCCs, because the opportunity costs incurred through late arrivals are relatively large.

One plausible way to deal with LCCs' higher possibility of late arrivals may be to introduce insurance to cover individuals' losses from such late arrivals. (Note 9) Through such insurance, individuals can reduce losses from late arrivals and they may hence prefer to choose LCCs.

The purpose of this research is to analyze an airline market in which both LCCs and FSCs coexist. In particular, this research investigates the effect of the introduction of insurance that covers losses from late arrivals. In relation to the 
introduction of this insurance, the following two questions are considered. The first question is how the demand for LCC changes when the insurance is introduced. We shed light especially on the exogenous situation in which the introduction of the insurance has a large impact. The second question is how to evaluate the effect of this insurance on investments by LCC to lower the possibility of late arrival. For example, an increase in the number of aircraft can lower the rate of late arrivals. From the viewpoint of such investments, the introduction of this type of insurance may not be desirable, because the incentive for implementing the investment might be lowered.

The remainder of this article is structured as follows. The model setting is explained in Section 2. Section 3 investigates the demand for an LCC with and without insurance to cover losses from late arrivals. Section 4 considers the situation in which an LCC can implement investments intended to lower the possibility of late arrival. Concluding remarks are given in Section 5.

\section{Model Setting}

Suppose there are two airlines (airline $L$ and $F$ ) that compete on the same route (for example, from Tokyo-Narita to Fukuoka). Airlines $L$ and $F$ stand for LCC and FSC, respectively. All individuals have the same initial wealth $w>0$ and they are assumed to purchase an air ticket from one or other airline, with $p_{i}$ representing the air ticket price of airline $i \in\{L, F\}$. In our model, air ticket prices are assumed to be exogenous and $0<p_{L}<p_{F}$. Although the air ticket price of airline $L$ is cheaper than that of airline $F$, airline $L$ has a possibility of late arrival. $\pi \in(0,1)$ represents the probability of on-time arrival; thus, the probability of late arrival is $1-\pi$. In contrast, it is assumed that airline $F$ is never delayed. When a late arrival occurs, individuals incur some disutility. The level of this disutility, which is denoted by $d$, is different among individuals. If an individual has a very tight time-bound schedule at the final destination, his/her disutility is large. In contrast, if an individual has no rigid schedule at the final destination, his/her disutility is small. For simplicity, it is assumed that the disutility $d$ is uniformly distributed on $[0,1]$.

In order to manage the risk of delays attached to airline $L$, we consider insurance to cover its passengers' losses from late arrivals. The insurance premium and the amount of insurance are $\gamma$ and $s$, respectively, and we assume $0<\gamma<s$. Thus, the insurance firm pays a constant amount of insurance regardless of the level of each individual's disutility. The utility function is represented by $u(\bullet)$; all individuals are assumed to be strictly risk averse, that is, $u^{\prime}(\bullet)>0$ and $u^{\prime \prime}(\bullet)<0$.

$E U_{L}^{j}$ represents the expected utility of individuals when they choose airline $L$ and purchase the insurance $(j=I)$ or do not purchase the insurance $(j=N)$. Each expected utility can be shown as

$$
\begin{gathered}
E U_{L}^{I}=(1-\pi) u\left(w-p_{L}-\gamma+s\right)+\pi u\left(w-p_{L}-\gamma\right)-(1-\pi) d . \\
E U_{L}^{N}=u\left(w-p_{L}\right)-(1-\pi) d .
\end{gathered}
$$

In contrast, the expected utility when individuals choose airline $F$, which is represented by $E U_{F}$, can be written as follows:

\section{Demand for the Low Cost Carrier}

$$
E U_{F}=u\left(w-p_{F}\right) .
$$

From equations (1) and (2), when the individual chooses airline $L$, the condition under which this individual wants to purchase insurance is as follows:

$$
E U_{L}^{I}>E U_{L}^{N} \Rightarrow(1-\pi) u\left(w-p_{L}-\gamma+s\right)+\pi u\left(w-p_{L}-\gamma\right)>u\left(w-p_{L}\right) .
$$

If inequality (4) is not satisfied, no individuals purchase the insurance. Thus, inequality (4) represents the condition for introducing insurance to the market.

First, consider the situation in which inequality (4) is not satisfied. In this situation, there is no insurance and each individual compares the two expected utilities shown in equations (2) and (3). It is easy to imagine that an individual whose disutility is relatively small (large) chooses airline $L(F)$. Let $d^{N}$ denotes the disutility level at which equations (2) and (3) are equal. Then, we show that:

$$
E U_{L}^{N}=E U_{F} \Rightarrow d^{N}=\frac{u\left(w-p_{L}\right)-u\left(w-p_{F}\right)}{1-\pi} .
$$

Thus, individuals whose disutility level is located within $\left\lfloor 0, d^{N}\right\rfloor$ choose airline $L$, while individuals whose disutility level is located within $\left[d^{N}, 1\right]$ choose airline $F$. 
Next, consider the situation in which inequality (4) is satisfied. In this situation, the insurance is introduced and each individual has an incentive to purchase insurance when he/she chooses airline $L$. Each individual compares the two expected utilities shown in equations (1) and (3). Let $d^{I}$ denotes the disutility level at which equations (1) and (3) are equal. Then, we show that:

$$
E U_{L}^{I}=E U_{F} \Rightarrow d^{I}=\frac{(1-\pi) u\left(w-p_{L}-\gamma+s\right)+\pi u\left(w-p_{L}-\gamma\right)-u\left(w-p_{F}\right)}{1-\pi} .
$$

We know that $d^{N}$ and $d^{I}$ represent the demand for airline $L$, because $d$ is uniformly distributed on [0,1]. In order to investigate the impact of the introduction of the insurance, two kinds of demand, represented by equations (5) and (6), are compared. Then,

$$
\tilde{d} \equiv d^{I}-d^{N}=\frac{(1-\pi) u\left(w-p_{L}-\gamma+s\right)+\pi u\left(w-p_{L}-\gamma\right)-u\left(w-p_{L}\right)}{1-\pi} .
$$

The inequality $d^{I}>d^{N}$ is always satisfied if inequality (4) is satisfied. This result implies that the introduction of the insurance enhances the demand for airline $L$. In order to investigate the impact of introducing the insurance, it is assumed that inequality (4) is always satisfied. Also, the following function, which represents the numerator in the equation (7), is considered:

$$
g \equiv(1-\pi) u\left(w-p_{L}-\gamma+s\right)+\pi u\left(w-p_{L}-\gamma\right)-u\left(w-p_{L}\right) .
$$

To confirm the effect of exogenous variables on the demand for airline $L$, comparative statics can be conducted as follows because equation (8) can be used instead of equation (7) except in the case of $\pi$.

$$
\begin{gathered}
\frac{\partial \tilde{d}}{\partial \pi}=\frac{u\left(w-p_{L}-\gamma\right)-u\left(w-p_{L}\right)}{(1-\pi)^{2}}<0, \\
\frac{\partial g}{\partial \gamma}=-(1-\pi) u^{\prime}\left(w-p_{L}-\gamma+s\right)-\pi u^{\prime}\left(w-p_{L}-\gamma\right)<0, \\
\frac{\partial g}{\partial s}=(1-\pi) u^{\prime}\left(w-p_{L}-\gamma+s\right)>0, \\
\frac{\partial g}{\partial p_{L}}=-(1-\pi) u^{\prime}\left(w-p_{L}-\gamma+s\right)-\pi u^{\prime}\left(w-p_{L}-\gamma\right)+u^{\prime}\left(w-p_{L}\right) .
\end{gathered}
$$

The implications of these equations are as follows. First, equation (9) indicates that the impact of introducing insurance becomes large when the possibility of late arrival is high. Second, equations (10) and (11) show that the impact of the introduction of insurance becomes large when the insurance premium rate, which is represented by $\gamma / s$, diminishes. Third, from equation (12), the relationship between the air ticket price of airline $L$ and the introduction of insurance is ambiguous. However, from detailed analysis, the following results can be derived. (Note 10) When $\pi$ is relatively small, $\partial g / \partial p_{L}>0$ is generally realized. In contrast, when $\pi$ is relatively large, $\partial g / \partial p_{L}<0$ may be realized. Last, the air ticket price of airline $F$ is not related to the impact of introducing insurance, because $\tilde{d}$ is not a function of $p_{F}$.

\section{Optimal Investment Level}

In this section, we consider the situation in which airline $L$ can make an investment intended to lower the possibility of late arrival. Increasing the number of aircraft is a typical strategy to lower the possibility of late arrivals, but some investment costs are necessary. Suppose that $k \equiv k(\pi)$ represents the investment cost function and assume that $k^{\prime}(\pi)>0$ and $k^{\prime \prime}(\pi)>0$.

First, consider the situation in which there is no insurance. The airline $L$ chooses an optimal investment level to maximize the following objective function $f^{N}$ :

$$
f^{N} \equiv d^{N}-k^{N}=\frac{u\left(w-p_{L}\right)-u\left(w-p_{F}\right)}{1-\pi}-k(\pi) .
$$

Then, the first-order condition of the equation (13) can be derived as

$$
\frac{\partial f^{N}}{\partial \pi}=\frac{u\left(w-p_{L}\right)-u\left(w-p_{F}\right)}{\left(1-\pi^{N}\right)^{2}}-k^{\prime}\left(\pi^{N}\right)=0
$$


where $\pi^{N}$ represents the possibility of on-time arrival when airline $L$ chooses its optimal investment level without insurance. Also, the second-order condition of equation (13) can be derived as

$$
\frac{\partial^{2} f^{N}}{\partial \pi^{2}}=\frac{2\left\{u\left(w-p_{L}\right)-u\left(w-p_{F}\right)\right\}}{(1-\pi)^{3}}-k^{\prime \prime}(\pi) .
$$

In the later discussion, it is assumed that the second-order condition for maximization is always satisfied, that is, $\partial^{2} f^{N} / \partial \pi^{2}<0$ when $\pi=\pi^{N}$. (Note 11)

Next, we consider the situation in which the insurance is introduced. Airline $L$ chooses the optimal investment level that maximizes the following objective function $f^{I}$ :

$$
f^{I} \equiv d^{I}-k^{I}=\frac{(1-\pi) u\left(w-p_{L}-\gamma+s\right)+\pi u\left(w-p_{L}-\gamma\right)-u\left(w-p_{F}\right)}{1-\pi}-k(\pi) .
$$

Then, the first-order condition of the equation (16) can be derived as

$$
\frac{\partial f^{I}}{\partial \pi}=\frac{u\left(w-p_{L}-\gamma\right)-u\left(w-p_{F}\right)}{\left(1-\pi^{I}\right)^{2}}-k^{\prime}\left(\pi^{I}\right)=0
$$

where $\pi^{I}$ represents the possibility of on-time arrival when airline $L$ chooses the optimal investment level with insurance. Also, the second-order condition of equation (16) can be derived as

$$
\frac{\partial^{2} f^{I}}{\partial \pi^{2}}=\frac{2\left\{u\left(w-p_{L}-\gamma\right)-u\left(w-p_{F}\right)\right\}}{(1-\pi)^{3}}-k^{\prime \prime}(\pi) .
$$

In the later discussion, it is assumed that the second-order condition for maximization is always satisfied, that is, $\partial^{2} f^{I} / \partial \pi^{2}<0$ when $\pi=\pi^{I}$. (Note 12)

From equation (14), we show

$$
k^{\prime}\left(\pi^{N}\right)\left(1-\pi^{N}\right)^{2}=u\left(w-p_{L}\right)-u\left(w-p_{F}\right) .
$$

Suppose the case in which $\pi^{I}=\pi^{N}$ obtains. Then, substituting equation (19) into equation (17), we have

$$
\left.\frac{\partial f^{I}}{\partial \pi}\right|_{\pi^{I}=\pi^{N}}=\frac{u\left(w-p_{L}-\gamma\right)-u\left(w-p_{L}\right)}{\left(1-\pi^{N}\right)^{2}} .
$$

If equation (20) is positive (negative), it means $\pi^{N}<(>) \pi^{I}$. We then find $\pi^{N}>\pi^{I}$ is surely realized, because equation (20) is always negative. From this discussion, we find that the introduction of the insurance lowers the optimal investment level of the airline $L$.

\section{Concluding Remarks}

The main results of this research are as follows. First, the introduction of insurance to cover individuals' losses from late arrivals increases the demand for the LCC. Second, the impact of introducing insurance becomes high when the possibility of late arrival is high and insurance premium rate is low, but the effect of the air ticket price of the LCC is ambiguous. Third, the introduction of insurance reduces the LCC's optimal investment for lowering the possibility of late arrival.

Our model sheds light on the impact of the introduction of insurance to cover passengers' losses from late arrivals. However, there are possible extensions to our model. For example, our model did not consider air ticket price competition, but in reality, LCC and FSC will compete with respect to air ticket prices. Another issue is that our model did not explicitly consider insurance premium levels and the amount of insurance. However, insurance firms actually decide the levels of insurance premium and amount of insurance with reference to the possibility of late arrivals. In this regard, we hypothesize that the introduction of insurance might provide an incentive to make investments intended to raise the possibility of on-time arrivals and lower the level of the insurance premium.

\section{Acknowledgements}

This work was supported by JSPS KAKENHI Grant Number 24730362. 


\section{References}

Han, H., Hyun, S. S., \& Kim, W. (2014). In-flight Service Performance and Passenger Loyalty: A Cross-national (China/Korea) Study of Travelers Using Low-cost Carriers. Journal of Travel \& Tourism Marketing, 31(5), 589-609.

Hanaoka, S., Takebayashi, M., Ishikura, T., \& Saraswati, B. (2014). Low-cost Carriers Versus Full Service Carriers in ASEAN: The Impact of Liberalization Policy on Competition. Journal of Air Transport Management, 40, 96-105.

Kim, Y., Kim, Y., \& Lee, Y. (2011). Perceived Service Quality for South Korean Domestic Airlines. Total Quality Management \& Business Excellence, 22(10), 1041-1056.

Murakami, H. (2011). Empirical Analysis of Inter-firm Rivalry between Japanese Full-service and Low-cost Carriers. Pacific Economic Review, 16(1), 103-119.

Nakabayashi Seminar (2015). A Study on Flight Insurance Introduced for Passengers of Low Cost Carriers in Japan. Study of Non-Life Insurance. Forthcoming (in Japanese).

O’Connell, J. F., \& Williams, G. (2005). Passengers' Perceptions of Low Cost Airlines and Full Service Carriers: A Case Study Involving Ryanair, Aer Lingus, Air Asia and Malaysia Airlines. Journal of Air Transport Management, $11(4), 259-272$.

Rupp, N. G., \& Sayanak, T. (2008). Do Low Cost Carriers Provide Low Quality Service? Revista de Análisis Económico, 23(1), 3-20.

Wu, C., \& Hayashi, Y. (2014). The Effect of LCCs Operations and Scheduled Services Deregulation on Air Charter Business in Japan. Journal of Transport Geography, 41, 37-44.

Notes

Note 1. See p. 122 of the following website (accessed on July 8, 2015) (in Japanese): www.mlit.go.jp/common/001042470.pdf

Note 2. The brief history of four new airlines in Japan-Hokkaido International Airlines, Skymark Airlines, Skynet Asia Airways, and Star Flyer - was described, for example, in Murakami (2011). Wu \& Hayashi (2014) summarized the characteristics of Japanese LCCs as of the end of December 2013.

Note 3. Air Asia Japan stopped services in October 2013, changed its name to Vanilla Air, and restarted services in December 2013.

Note 4. For a more detailed comparison between LCCs and FSCs, see O'Connell \& Williams (2005, Table 1 (p. 260)). Kim et al. (2011) investigated the perceived service quality of LCCs and FSCs in Korean domestic airlines. Han et al. (2014) conducted the questionnaires to Chinese and Korean passengers and investigated in-flight service performance of LCCs. Hanaoka et al. (2014) analyzed the ASEAN airline market including both LCCs and FSCs.

Note 5. September 15, 2015 is a weekday (Tuesday) and is two months ahead of the search day (July 16, 2015). The following two URLs are the webpages of Japan Airline and Jetstar Japan (accessed on July 16, 2015):

Japan Airline: http://www.jal.co.jp/en/

Jetstar Japan: http://www.jetstar.com/jp/en/home

Note 6. The Japan Airline price includes an early reservation discount. Jetstar Japan has six flights in a day with a different ticket price for each flight. The lowest and highest prices are 6,390 and 9,290 Japanese yen, respectively.

Note 7. Each average rate of late departure is calculated by the data at the following website (accessed on July 8, 2015) (in Japanese):

http://www.mlit.go.jp/report/press/kouku04_hh_000110.html

Note 8. In contrast, Rupp \& Sayanak (2008) insisted that LCCs in U.S. domestic flights do not have such a disadvantage and that their flight schedules are more reliable.

Note 9. The idea of introducing this insurance is strongly indebted to the Nakabayashi Seminar (2015). The insurance discussed in this article is different from missed flight cover, which was introduced by easyJet. According to the explanation at the website of easyJet (http://www.easyjet.com/en/book/ missed-flight-cover) and an article on the Guardian website (July (http://www.theguardian.com/money/2012/jul/12/missed-flight-insurance-cover-easyjet) (both websites accessed on July 8, 2015), missed flight cover focuses on flights missed due to the late arrival of passengers at the departure airport due to oversleeping, being stuck in traffic, and so on.

Note 10. The detailed analysis is conducted in Appendix A. 
Note 11. For a detailed discussion of the second-order condition, see Appendix B.

Note 12. For a detailed discussion of the second-order condition, see Appendix B.

\section{Appendix A}

It is clear that $\partial g / \partial p_{L}>0$ is satisfied when $\pi$ is relatively small, because $0<u^{\prime}\left(w-p_{L}-\gamma+s\right)<u^{\prime}\left(w-p_{L}\right)<u^{\prime}\left(w-p_{L}-\gamma\right)$. A typical example can be shown in the case of $\pi \approx 0$, then $\partial g / \partial p_{L} \approx-u^{\prime}\left(w-p_{L}-\gamma+s\right)+u^{\prime}\left(w-p_{L}\right)>0$ is realized.

In contrast, $\partial g / \partial p_{L}<0$ may be realized when $\pi$ is relatively large, because the absolute values of the first term and second term of the right-hand side in equation (12) become small and large respectively. However, it is not certain whether a value of $\pi$ for realizing $\partial g / \partial p_{L}<0$ always exists. In order to investigate this existence problem, we let $\hat{\pi}$ denote the value of $\pi$ for which $\partial g / \partial p_{L}=0$. From inequality (4), we have

$$
\pi<\bar{\pi} \equiv \frac{u\left(w-p_{L}-\gamma+s\right)-u\left(w-p_{L}\right)}{u\left(w-p_{L}-\gamma+s\right)-u\left(w-p_{L}-\gamma\right)} .
$$

Then, if $\hat{\pi}>\bar{\pi}, \hat{\pi}$ cannot satisfy inequality (4). This implies that there is no possibility to realize $\partial g / \partial p_{L}<0$. In contrast, if $\hat{\pi}<\bar{\pi}$, there exists $\hat{\pi}$ that satisfies inequality (4). This implies that $\partial g / \partial p_{L}<0$ can be realized when $\pi$ is relatively large.

In order to know which of $\hat{\pi}$ or $\bar{\pi}$ is larger, substituting $\pi=\bar{\pi}$ into equation (12), we have

$$
\begin{gathered}
\left.\frac{\partial g}{\partial p_{L}}\right|_{\pi=\bar{\pi}}=\left\{u^{\prime}\left(w-p_{L}\right)-u^{\prime}\left(w-p_{L}-\gamma+s\right)\right\} \\
+\frac{\left\{u\left(w-p_{L}-\gamma+s\right)-u\left(w-p_{L}\right)\left\{u^{\prime}\left(w-p_{L}-\gamma+s\right)-u^{\prime}\left(w-p_{L}-\gamma\right)\right\}\right.}{u\left(w-p_{L}-\gamma+s\right)-u\left(w-p_{L}-\gamma\right)} .
\end{gathered}
$$

From equation (A2), we cannot determine whether $\hat{\pi}$ or $\bar{\pi}$ is larger, because the terms in braces and the third term of the right-hand side in equation (A2) are positive and negative, respectively. We thus find that the sign of $\partial g / \partial p_{L}$ is indeterminate when $\pi$ is relatively large.

\section{Appendix B}

In the later discussion, we only check equation (15), because the form of equations (15) and (18) is the same. In order to satisfy the second-order condition, the following inequality must be satisfied:

$$
\frac{2\left\{u\left(w-p_{L}\right)-u\left(w-p_{F}\right)\right\}}{\left(1-\pi^{N}\right)^{3}}-k^{\prime \prime}\left(\pi^{N}\right)<0 \Rightarrow k^{\prime \prime}\left(\pi^{N}\right)\left(1-\pi^{N}\right)^{3}-2\left\{u\left(w-p_{L}\right)-u\left(w-p_{F}\right)\right\}>0 .
$$

From equation (14), we have

$$
u\left(w-p_{L}\right)-u\left(w-p_{F}\right)=k^{\prime}\left(\pi^{N}\right)\left(1-\pi^{N}\right)^{2} .
$$

Substituting equation (B2) into inequality (B1), we obtain

$$
k^{\prime \prime}\left(\pi^{N}\right)\left(1-\pi^{N}\right)^{3}-2 k^{\prime}\left(\pi^{N}\right)\left(1-\pi^{N}\right)^{2}=\left(1-\pi^{N}\right)^{2}\left\{k^{\prime \prime}\left(\pi^{N}\right)\left(1-\pi^{N}\right)-2 k^{\prime}\left(\pi^{N}\right)\right\}>0 .
$$

Thus, the condition under which equation (15) is satisfied can be written as

$$
k^{\prime \prime}\left(\pi^{N}\right)\left(1-\pi^{N}\right)-2 k^{\prime}\left(\pi^{N}\right)>0 \Rightarrow \pi^{N}<1-\frac{2 k^{\prime}\left(\pi^{N}\right)}{k^{\prime \prime}\left(\pi^{N}\right)} .
$$

We find that inequality (B4) is satisfied when the absolute value of the second term of the right-hand side in the inequality (B4) is small. A higher convexity of the investment cost function is an example of a way to satisfy inequality (B4).

\section{(cc) $\mathrm{Br}$}

This work is licensed under a Creative Commons Attribution 3.0 License. 